\title{
Speaking no truth to power in a time of coup: Myanmar's Human Rights Commission
}

Edition 6, 2021

Dr Jonathan Liljeblad

DOI: 10.37839/MAR2652-550X6.4

On February 1, 2021, the Myanmar military (Tatmadaw) conducted a coup to overthrow the civilian government led by Daw Aung San Suu Kyi and the National League for Democracy (NLD). The military coup was met with widespread resistance encompassing nationwide street protests, a civil disobedience movement across all ministries and all levels of government, strikes organised by an alliance of civil society organisations under a General Strike Committee, mobilisation of ethnic armed organisations, a revolt by Myanmar diplomats, and formation of a Committee Representing the Pyidaungsu Hluttaw comprised of parliamentary members claiming to represent an independent civilian government. The military regime has responded with violence, with increasing allegations of growing human rights violations despite international condemnation.

In the midst of the crisis, the Myanmar National Human Rights Commission (MNHRC) has been noticeably silent. Following the coup, the Tatmadaw removed or replaced civilian ministers and reconstituted the country's Union Election Commission. However, the Tatmadaw retained the existing members of the Supreme Court, Anti-Corruption Commission, and MNHRC.

The retention of the MNHRC occurred even though it holds a mandate to promote human rights and a complement of commissioners selected by the deposed NLD government, both of which would suggest motivations to speak out against the 
military's violence against unarmed peaceful protests in the wake of the coup. The MNHRC's inaction is also out of step with other national human rights institutions in the Asia region that have been vocal in the face of repressive regimes. The MNHRC's apparent quiescence has been noted by both domestic and international human rights supporters, with calls by various non-government organisations for the MNHRC to address human rights violations and for the international community to terminate relations with the MNHRC for its inaction.

The situation poses implications for the broader Asia region with respect to the role of human rights bodies. In particular, it raises issues regarding the expectations of human rights institutions in relation to regimes inimical to human rights. What should be done when an entity entrusted to defend human rights fails to fulfil its mission? Such reflection vis-à-vis the current status of the MNHRC ties to considerations of similar human rights bodies facing authoritarian regimes in other parts of Asia-a growing concern given the trends of declining liberalism and democracy across the region.

\section{National Human Rights Institutions}

The MNHRC is a National Human Rights Institution (NHRI). NHRIs are tasked with promoting international human rights norms at national levels. As defined by the 1993 United Nations General Assembly Principles Relating to the Status of National Institutions (Paris Principles), an NHRI is formed by statutory or constitutional mandate but is expected to be an entity independent of the state. In addition, the Paris Principles place duties on NHRIs in terms of advising the state regarding human rights, ensuring harmonisation of national laws with state obligations to international human rights instruments, encouraging ratification and implementation of international human rights instruments, contributing to state reports to international and regional bodies regarding human rights, cooperating with other entities promoting human rights, and teaching and publicising human rights. In fulfilling such duties, the Paris Principles call on NHRIs to operate of their 
own volition to consider questions, obtain information, conduct investigations, hear complaints, and consult with other bodies. In doing so, the Paris Principles also require that an NHRI be pluralist in representing the diverse social forces of civil society in the promotion of human rights.

NHRIs are subject to monitoring and evaluation via a periodic accreditation process hosted by the Global Alliance of National Human Rights Institutions (GANHRI), a private entity which reviews each NHRI once every five years for its compliance with the Paris Principles. As of 2021, GANHRI recognises 117 members spread throughout the world. GANHRI's peer-review accreditation system places an NHRI into one of three categories: ' $A$ ' indicates full compliance with the Paris Principles, ' $B$ ' reflects partial compliance, and ' $C$ ' marks a total failure to adhere to the Paris Principles. NHRIs with an 'A' accreditation are allowed to participate in the proceedings of GANHRI and the Human Rights Council. In contrast, NHRIs with a ' $\mathrm{B}$ ' are restricted to observer status in GANHRI and Human Rights Council proceedings, and those with a ' $\mathrm{C}$ ' are not allowed to hold rights or privileges in any UN human rights fora.

The MNHRC currently has a 'B' rating. In justifying the rating, GANHRI noted that the MNHRC suffers from a lack of transparency and pluralism in the selection of its members. In addition, GANHRI observed that the MNHRC's independence is hampered by continuing state control over its budget and that its mandate is constrained by a requirement that it provide prior notification of its investigations. Further, GANHRI criticised the MNHRC as insufficiently addressing civil unrest against ethnic minorities, inadequate engagement with all branches of the state, and inadequate coordination with international human rights institutions.

\section{Status of the MNHRC}

GANHRI's critiques may have been a portent of the MNHRC's current inaction in the wake of the February 1 military coup. The MNHRC's 'B' rating, however, signifies 
partial fulfilment of the Paris Principles, and suggests that GANHRI had recognised that in the years before the coup the MNHRC had been undertaking some measure of action as an NHRI. In contrast, the MNHRC's current silence is less reflective of partial fulfilment and more suggestive of a complete failure to uphold the NHRI duties prescribed by the Paris Principles.

The MNHRC's current quiescence becomes acute when compared to its recent past before the February military coup. For example, in 2020 the MNHRC examined over 2,300 claims of human rights violations and secured 386 government responses to inquiries of alleged human rights violations. The latter figure was an increase from the 204 responses made in 2019, 22 in 2018, and 1 in 2017. Such progress occurred despite the MNHRC's struggles with the uncertainties of Myanmar's context. Myanmar has a history of struggles with human rights, such that the MNHRC works within a limited space demarcated by a state and a society unfamiliar or resistant to its work to promote international human rights norms. In addition, Myanmar's underdevelopment renders human rights as one of multiple priorities calling for support, forcing the MNHRC to compete against other issues for the attention of political leaders. Moreover, Myanmar has a complex political environment, with multiple ethnic armed organisations, diverse civilian and military factions, and various international actors fostering an unstable environment. The MNHRC's performance under such circumstances suggests some level of capacity and commitment to fulfil its role as an NHRI, and hence some amount of activism consistent with GANHRI accreditation under the Paris Principles. In comparison to such activism, the post-coup silence of the MNHRC becomes stark, particularly in the face of growing allegations of human rights violations by the Tatmadaw calling for NHRI response.

The current situation becomes more disconcerting when viewed relative to the work of other NHRIs in Southeast Asia against their own domestic challenges. In particular, ASEAN hosts six NHRIs in Indonesia, Malaysia, Myanmar, Philippines, Thailand, and Timor-Leste; and four of them hold ' $A$ ' ratings, with the only exceptions being the ' $\mathrm{B}$ ' rankings of Myanmar and Thailand. Similar to the MNHRC, 
the GANHRI assessed the Thai Human Rights Commission (THRC) as a 'B' because of concerns over its lack independence, insufficiently inclusive selection process for commissioners, and inadequate activism. Outside of the MNHRC and THRC, the status of ASEAN's NHRIs indicates a general GANHRI recognition of adherence to the expectations in the Paris Principles. This comes despite efforts by ASEAN states to disregard, co-opt, or antagonise NHRI missions. Disregard involves state offices providing desultory responses to NHRI inquiries or refusing engagement with an NHRI altogether. Co-optation occurs via state manipulation of NHRI staffing, with the goal of:

- placing only political allies onto NHRIs to ensure acquiescence to regime leaders,

- installing judicial officers onto NHRIs so as to limit human rights to the provisions of state law, or

- circumscribing NHRI leadership by classifying administrative personnel as civil servants of state bureaucracy.

Antagonism is politically-motivated use of disciplinary procedures by a regime against NHRI leadership, state restriction of NHRI funding, state reduction of NHRI staffing, or outright dissolution of NHRIs.

The success of the majority of ASEAN NHRIs in achieving GANHRI's 'A' accreditation points to the effectiveness of their respective efforts to maintain their duties under the Paris Principles despite the strategies of hostile states. Against such records, the current inaction by the MNHRC becomes an aberration outside regional NHRI trends.

Adding to the above concerns is the observation that there seems to be more action related to the February coup from human rights institutions outside Myanmar than there is from the MNHRC itself. Of particular note is the ASEAN regional human rights institution, the ASEAN Intergovernmental Commission on Human Rights (AICHR), whose current and past members have issued statements describing the 
coup and the Tatmadaw's subsequent conduct to be violations of the principles of democracy, rule of law, governance, and human rights contained within both the ASEAN Charter and the ASEAN Declaration of Human Rights. The resolute assertiveness of such actors contrasts markedly with the silence of the MNHRC.

\section{What the MNHRC should do}

It is possible to construe the MNHRC's inaction as a response to circumstances in the wake of the coup, in that the MNHRC's past record was a reflection of a civilian government amenable to human rights and the coup marked the return of a military that has consistently proven itself hostile to human rights. Given the constraints on the MNHRC in terms of state control over its budget and the requirement of notice prior to its investigations, the prospects for the MNHRC as an institution are dimmed with a state controlled by a military regime inimical to its foundational purpose.

However, a hostile regime may explain impairment of an NHRI's powers but it does not justify abandonment of an NHRI's duties. The NHRIs of ASEAN are testament to the continuing work of NHRIs despite the pressures of hostile regimes, and so do not excuse the MNHRC's apparent reticence. In keeping with the Paris Principles, the enabling law of the MNHRC gives it a broad mandate to defend and promote human rights. In the absence of state action or cooperation, the MNHRC can initiate its own inquiries and can hear complaints. In the event that limitations of staff or resources prevent either, the MNHRC is still obliged to compile information on alleged human rights violations to be shared with international human rights institutions.

Even with no staff or resources, MNHRC members can still function as individuals to fulfil the institution's duties to the Paris Principles, if not in advising, monitoring, investigation, or hearing of complaints then in coordinating with international actors to assert human rights within the country. At a minimum the individual commissioners of the MNHRC retain the capacity and the duty to issue statements 
about human rights issues occurring in Myanmar. So far the MNHRC has not done so.

The growing allegations of human rights violations by the Tatmadaw since the February coup constitute an increasingly urgent situation for human rights in Myanmar. Inaction by the MNHRC runs counter to the role of NHRIs as representatives of an international human rights system and defeats the central purpose of NHRIs to promote human rights within states. In doing so, it risks rendering the existence of NHRIs meaningless.

\section{Implications beyond Myanmar}

What should be done when an NHRI fails in its duties? Non-state actors such as NGOs have little power against NHRIs beyond public shaming strategies. The Joint Statement of the MNHRC Working Group and its allied Civil Society Organisations, a statement by 54 NGOs calling on the MNHRC to denounce the military coup, exemplifies this strategy. However, it also calls for parties that wield various forms of influence over the MNHRC-such as GANHRI with its accreditation system; the South East Asia National Human Rights Institutions Forum (SEANF) and Asia Pacific Forum (APF), which provide coordination, networking, advice, and technical support; and international aid programs, which provide funding and resources for capacity-building - to terminate relations with the MNHRC. This constitutes punitive measures for its inactions vis-à-vis the Tatmadaw, with the consequence being not just public shaming but also a constriction of international support.

Such measures are feasible. GANHRI has sanctions it can impose on NHRIs that fail to adhere to the Paris Principles in the form of either a downgrade to a ' $\mathrm{C}$ ' accreditation rating or outright suspension. Similarly, SEANF and APF have discretion to undertake action in circumstances where NHRI's are not fulfilling their respective organisational purposes. International aid providers also have the ability to apply their own prescriptions for violations of aid conditions. 
The notion of punitive action, however, is not straightforward in that it ignores the aspect of intent. It seems appropriate to take action against an NHRI that is willfully failing its duties, but less appropriate to punish an NHRI if it is being coerced. Unless consideration is given to the circumstances, responses may not address the issues and causes underlying NHRI behaviour. For the present situation in relation to the MNHRC, the decisions of GANHRI, SEANF, APF, and other international actors requires ascertainment as to the reasons for the MNHRC's lack of action.

The issues with the MNHRC and Myanmar should not be seen as isolated phenomena, but rather as additions to a broader trend of declining liberal democracy in Asia. As noted by Freedom House, the Lowy Institute, the East Asia Foundation, Asian Barometer, and Bertelsmann Stiftung, Asia is experiencing a rise of authoritarianism driven by illiberal populist movements and autocratic regimes exacerbated by the COVID-19 pandemic crisis. Such growth, however, is not inevitable but is contested by those trying to revive democratic principles and liberal values. The work of ASEAN NHRIs against the hostile strategies of their respective states exemplify the form of such struggles. For those who seek to reverse the rise of authoritarianism in Asia, it is imperative to support human rights ideals and those promoting them. In situations where action is not forthcoming from the entities specifically assigned to undertake them, international action is needed to ensure the defence of human rights and stem the decline of liberal democracy in Asia.

Related webinar: Human rights and democratic regression in Asia.

Image: Soldier with assault rifle and flag of Myanmar on military uniform. Credit: Bumble Dee/Shutterstock. 